\title{
Perancangan Aplikasi Sistem Pakar Diagnosa Awal Kanker Reproduksi Wanita Dengan Metode Certainty Factor
}

\author{
Sukmawati Anggraeni Putri ${ }^{1}$, Elin Panca Saputra ${ }^{2}$ \\ ${ }^{1}$ Program Studi Sistem Informasi, STMIK Nusa Mandiri Jakarta, Indonesia \\ 2 Program Studi Manajemen Informatika, AMIK BSI Jakarta, Indonesia \\ ${ }^{1}$ Jl. Damai No.8 Warung Jati Barat, Jakarta Selatan, 12950, Indonesia \\ sukmawati@ nusamandiri.ac.id ${ }^{1}$; elin.epa@bsi.ac.id ${ }^{2}$
}

\begin{abstract}
Abstrak
Hingga saat ini penyakit kanker merupakan salah satu penyakit yang banyak diderita oleh masyarakat Indonesia, terutama pada kanker serviks (mulut rahim) yang diderita oleh wanita Indonesia. Tidak hanya kanker serviks yang diderita oleh wanita Indonesia, tetapi juga penyakit lainnya yang menyerang organ reproduksi wanita lainnya. Penyakit tersebut seperti, kanker rahim, kanker indung telur, kanker Endometrium, kanker vagina, kista ovarium dan mioma. Untuk mencegah jumlah angka kematian penderita, tentunya diagnosa awal sebagai salah satu solusinya. Seperti yang diusulkan pada penelitian ini dalam membangun aplikasi sistem pakar diagnosa awal kanker reproduksi wanita. Sistem pakar ini memberikan nilai tambah pada teknologi untuk membantu dalam menangani era informasi yang semakin canggih. Aplikasi Sistem Pakar ini menghasilkan keluaran berupa kemungkinan penyakit kanker reproduksi wanita yang diderita berdasarkan gejala yang dirasakan oleh pasien. Sistem ini juga memperoleh hasil kepercayaan terhadap kemungkinan penyakit kanker reproduksi wanita yang diderita oleh pasien berdasarkan gejala yang dirasakan oleh pasien. Besarnya nilai kepercayaan tersebut merupakan hasil perhitungan dengan menggunakan metode Certainty Factor.
\end{abstract}

Kata Kunci: Kanker Reproduksi Wanita, Sistem Pakar, dan Metode Certainty Factor.

\section{Abstract}

Until now, cancer is one that suffered by the people of Indonesia, especially in cervical cancer (cervix) suffered by Indonesian women. Not only cervical cancer suffered by Indonesian women, but also other diseases that attack the female reproductive organs. Such diseases, cervical cancer, ovarian cancer, endometrial cancer, vaginal cancer, ovarian cysts and myomas. To prevent the number of deaths of patients, of course the initial diagnosis as one of the solutions. As used in this study in development an early diagnosis system of female reproductive cancer. This expert system adds value to the technology to assist in the handling of an increasingly sophisticated information age. This Expert System Application generates an Update that enables patients who suffer from symptoms that are felt by the patient. This system is also a result of the necessity of women suffering from cancer experienced by patients. The amount of trust value is the result of calculation using Certainty Factor method.

Keywords : Female Reproductive Cancer, Expert System, and Certainty Factor Method

\section{PENDAHULUAN}

Kanker dapat menyerang semua lapisan masyarakat tanpa mengenal status sosial, umur dan jenis kelamin. Dari data yang ada, kaum wanita paling banyak terkena kanker. Kaum wanita cukup rentan terhadap serangan kanker, terutama organ vital seperti payudara dan organ reproduksi seperti rahim, indung telur dan vagina. Pendeteksian penyakit kanker sedini mungkin, menjadi salah satu upaya pencegahan dari penyebaran penyakit kanker tersebut. Kanker reproduksi wanita [1] [2], seperti penyakit kanker mulut rahim, kanker rahim, kanker indung telur, kanker endometrium, kanker vagina, kista ovarium dan mioma.

Oleh karenanya, pada penelitian ini memberikan gagasan untuk membangun aplikasi yang dapat mendiagnosa awal dari penyakit kanker pada organ reproduksi wanita berdasarkan berdasarkan metode certainty factor. Aplikasi yang digagas berbasis online, memberikan kemudahan bagi msyarakat luas tanpa membutuhkan biaya yang banyak dalam mendiagnosa penyakit kanker reproduksi wanita sejak dini.

Sedangkan metode certainty factor telah banyak digunakan oleh peneliti sebelumnya diberbagai bidang dan menghasilkan akurasi yang akurat pada proses presentase prediksi. Seperti penelitian yang dilakukan oleh Sthepahine [3] bahwa metode certainty factor menunjukkan keakuratan $80 \%$ untuk mendeteksi resiko penyakit asteoporosis dan osteoarhritis. Penelitian lain menunjukkan hasil yang sama baiknya, yaitu penelitian yang dilakukan oleh Kusrini [4].

Sehingga diharapkan dengan menggunakan metode certainty factor, aplikasi sistem pakar diagnosa awal kanker reproduksi wanita ini dapat memberikan kemudahan bagi wanita untuk mengetahui sejak awal diagnosa kanker tersebut. Sehingga penyebaran penyakit kanker tersebut dapat dilakukan pengobatan dengan cepat dan 
tepat. Sebelum sel kanker tersebut menyebar keseluruh tubuh pasien, sehingga dapat mencegah angka kematian yang semakin meningkat setiap tahunnya.

\section{TEORITIS}

\subsection{Sistem Pakar}

Sistem pakar (expert system) menurut Kusrini [4] merupakan sistem yang berusaha mengadopsi pengetahuan manusia komputer, agar komputer dapat menyelesaikan masalah seperti yang biasa dilakukan oleh para ahli. Dalam penelitian yang dilakukan oleh [4] pengertian, ciri-ciri dan keuntungan sistem pakar, dari beberapa ahli yaitu sebagai berikut:

a. Menurut Durkin : Sistem pakar adalah suatu program komputer yang dirancang untuk memodelkan kemampuan penyelesaian masalah yang dilakukan oleh seorang pakar.

b. Menurut Giarratano dan Riley [5]: Sistem pakar adalah suatu sistem komputer yang bisa menyamai atau meniru kemampuan seorang pakar.

\subsection{Metode Faktor Kepastian (Certainty Factor)}

Certainty Factor (CF) [4][3] diperkenalkan oleh Shortliffe Buchanan dalam pembuatan MYCIN. Certainty Factor (CF) merupakan nilai parameter klinis yang diberikan MYCIN untuk menunjukkan besarnya kepercayaan. Certainty Factor didefinisikan sebagai berikut [5]:

$\mathrm{CF}[\mathrm{H}, \mathrm{E}]=\mathrm{MB}[\mathrm{H}, \mathrm{E}]-\mathrm{MD}[\mathrm{H}, \mathrm{E}]$

Dengan:

$\mathrm{CF}[\mathrm{H}, \mathrm{E}]=$ faktor kepastian dari hipotesis $\mathrm{H}$ yang dipengaruhi oleh gejala (evidence) E. Besarnya CF berkisar antara - 1 sampai dengan 1 . Nilai -1 menunjukkan ketidakpercayaan mutlak, sedangkan nilai 1 menunjukkan kepercayaan mutlak.

$\mathrm{MB}[\mathrm{H}, \mathrm{E}]=$ ukuran kenaikan kepercayaan (measure of increased belief) terhadap hipotesis $\mathrm{H}$ yang dipengaruhi oleh gejala E.

$\mathrm{MD}[\mathrm{H}, \mathrm{E}]=$ ukuran kenaikan ketidakpercayaan (measure of increased disbelief) terhadap hipotesis $\mathrm{H}$ yang dipengaruhi oleh gejala E.

Menurut [3] beberapa evidence dikombinasikan untuk menentukan CF dari suatu hipotesis. Jika e1 dan e2 adalah observasi, maka:

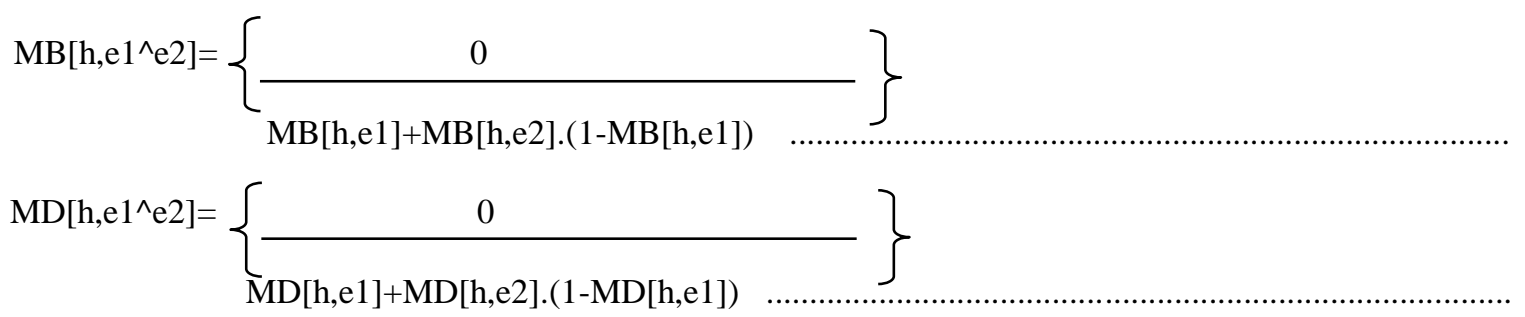

\subsection{Penyakit Kanker Reproduksi Wanita}

Dalam pengertian sederhana, kanker adalah sel yang tumbuh terus-menerus secara tidak terkendali, tidak terbatas dan tidak normal (abnormal) [2]. Penyakit kanker dapat menyerang semua lapisan masyarakat. Begitu pula dengan pria maupun wanita dapat terserang penyakit yang paling banyak ditakuti ini. Namun, berdasarkan data yang ada diperkirakan sekitar $60 \%$ penderita kanker di Indonesia adalah wanita [1].

Kanker bisa menyerang jaringan dalam berbagai organ tubuh, termasuk organ reproduksi wanita, yang terdiri dari payudara, rahim, indung telur dan vagina [6]. Organ reproduksi tersebut sangat penting karena menjadi identitas kesempurnaan seorang wanita. Penyakit kanker reproduksi wanita seperti [2], penyakit kanker mulut rahim, kanker rahim, kanker indung telur, kanker Endometrium, kanker vagina, kista ovarium dan mioma.

\section{ANALISA DAN PEMBAHASAN}

Pada tahap analisa sistem, data yang diperoleh dalam penelitian ini melalui studi lapangan ke pakar yang mengerti mengidentifikasi gejala penyakit kanter pada organ reproduksi wanita. Selain itu juga ditunjang dengan studi 
literatur mengenai penyakit dan gejala kanker pada organ reproduksi wanita. Seperti, buku maupun artikel ilmiah pada penelitian sebelumnya. Proses inti dari sistem ini adalah proses penalaran forward chaining. Sistem akan melakukan penalaran untuk menentukan jenis penyakit kanker reproduksi wanita yang diderita beserta pengobatan herbal dan nilai kepercayaan berdasarkan gejala yang dimasukan oleh user. Pada sistem telah disediakan aturan basis pengetahuan untuk penelusuran jenis penyakit. Data keluaran dari sistem ini adalah hasil diagnosa dari gejala yang dirasakan user yang berupa kemungkinan penyakit reproduksi wanita, keterangan tentang jenis penyakit reproduksi wanita yang diderita, dan nilai kepercayaan berdasarkan metode certainty factor.

Dalam perancangan ini kaidah produksi dituliskan dalam bentuk pernyataan JIKA [premis] MAKA [konklusi]. Sedangkan gejala tersebut dihubungkan dengan menggunakan operator logika DAN. Adapun bentuk pernyataannya adalah:

JIKA [gejala1] DAN [gejala2] MAKA [penyakit].

Dari bentuk kaidah produksi diatas, dapat diterapkan seperti contoh kaidah di bawah ini:

Kaidah1:

JIKA haid tidak normal, jumlahnya banyak

DAN sering nyeri di bagian bawah perut, DAN sering sakit serta berat pada panggul

DAN siklus haid tidak lancar, MAKA kista ovarium

Pengkonversian kaidah produksi menjadi tabel penyakit kanker reproduksi wanita dapat dilihat pada Tabel 1. Baris menunjukkan gejala dan kolom menunjukkan penyakit reproduksi wanita [2], [6].

Tabel 1. Penyakit

\begin{tabular}{|l|l|}
\hline Kode Rule & Nama Penyakit/ Kesimpulan \\
\hline P001 & Kanker Leher/ Mulut Rahim \\
\hline P002 & Kanker Rahim \\
\hline P003 & Kanker Indung Telur \\
\hline P004 & Kanker Endometrium \\
\hline P005 & Kanker Vagina \\
\hline P006 & Kista Ovarium \\
\hline P007 & Mioma \\
\hline
\end{tabular}

Tabel 2. Tabel Relasi

\begin{tabular}{|c|c|c|c|c|c|c|c|c|}
\hline Ho. & GEJALA - GEJALA & P001 & P002 & P003 & P004 & P005 & P006 & P007 \\
\hline G001 & Ada benjolan abnormal pada vagina & & & & & $\mathrm{x}$ & & \\
\hline G002 & Anemia & & & & & & & $x$ \\
\hline G003 & Berat badan menurun & & & $x$ & & & & \\
\hline G004 & Haid tidak normal dan dalam jumlah banyak & & $\mathrm{x}$ & & & & $\mathrm{x}$ & $\mathrm{x}$ \\
\hline G005 & Keluar keputihan berwarna kuning kemerahan. & $x$ & $\mathrm{x}$ & & $x$ & $x$ & & \\
\hline G006 & Keluar darah serta sakit saat buang air kecil & & & & $x$ & & & \\
\hline G007 & Keputihan berbau sangat menyengat. & $\mathrm{x}$ & & & & & & \\
\hline G008 & Nafsu makan hilang & & & $\mathrm{x}$ & & & & \\
\hline Go09 & Perut terlihat bengkak & & & $\mathrm{x}$ & & & & \\
\hline G010 & Sakit pada saat buang air kecil & & $\mathrm{x}$ & & & $\mathrm{x}$ & & \\
\hline G011 & Sakit punggung pada bagian bawah & & & & $\mathrm{x}$ & & & \\
\hline G012 & Saluran pencernaan terganggu terus-menerus & & & $x$ & & & & $x$ \\
\hline G013 & Sesak nafas dan demam & & & $\mathrm{x}$ & & & & \\
\hline G014 & Sering buang air kecil & & & $\mathrm{x}$ & & & & $x$ \\
\hline G015 & Sering pusing dan suhu badan naik & & & & & & & $x$ \\
\hline G016 & Sering gatal yang berlebihan di dalam vagina. & $\mathrm{x}$ & & & & & $\mathrm{x}$ & \\
\hline G017 & Sering sakit sangat saat haid di perut bawah & & & & $\mathrm{x}$ & & & \\
\hline G018 & Sering nyeri di bagian bawah perut. & $x$ & & & & $x$ & & \\
\hline G019 & Sering sakit serta berat pada panggul & & & $\mathrm{x}$ & & $x$ & $x$ & $\mathrm{x}$ \\
\hline G020 & Sering nyeri saat melakukan hubungan seksual & & & $\mathrm{x}$ & $\mathrm{x}$ & & $\mathrm{x}$ & \\
\hline G021 & Sering pendarahan setelah melakukan hubungan seksual. & $\mathrm{x}$ & $x$ & & & & & \\
\hline G022 & Sering pendarahan pada masa menopause. & $x$ & $x$ & & & & & \\
\hline G023 & Sering pendarahan di antara dua siklus menstruasi & $x$ & $x$ & & $\mathrm{x}$ & & & \\
\hline G024 & Sering pendarahan pada vagina & & & $x$ & & $x$ & & \\
\hline G025 & Siklus menstruasi tidak lancar & & & & & & $x$ & \\
\hline G026 & Sulit buang air besar & & & & $\mathrm{x}$ & & & \\
\hline G027 & Terasa sangat nyeri saat & & & & & & & $\mathrm{x}$ \\
\hline G028 & Timbul koreng di bagian dalam vagina. & $x$ & & & & & & \\
\hline G029 & Timbul luka pada lapisan vagina & & & & & $\mathrm{x}$ & & \\
\hline
\end{tabular}


Basis pengetahuan yang bersifat dinamis, sehingga pakar dapat menambah atau mengubah basis pengetahuan tersebut sesuai data yang baru. Dalam perancangan sistem pakar ini menggunakan metode penalaran pelacakan maju (Forward Chaining) yaitu dimulai dari sekumpulan fakta-fakta tentang suatu gejala yang diberikan oleh user sebagai masukan sistem, kemudian dilakukan pelacakan yaitu perhitungan sampai tujuan akhir berupa diagnosis kemungkinan penyakit kanker reproduksi wanita yang diderita dan nilai kepercayaan.

Untuk proses penarikan kesimpulan dapat dilihat pada Gambar 5 yang merupakan solusi sistem pakar dengan menggunakan flowchart atau diagram alir.

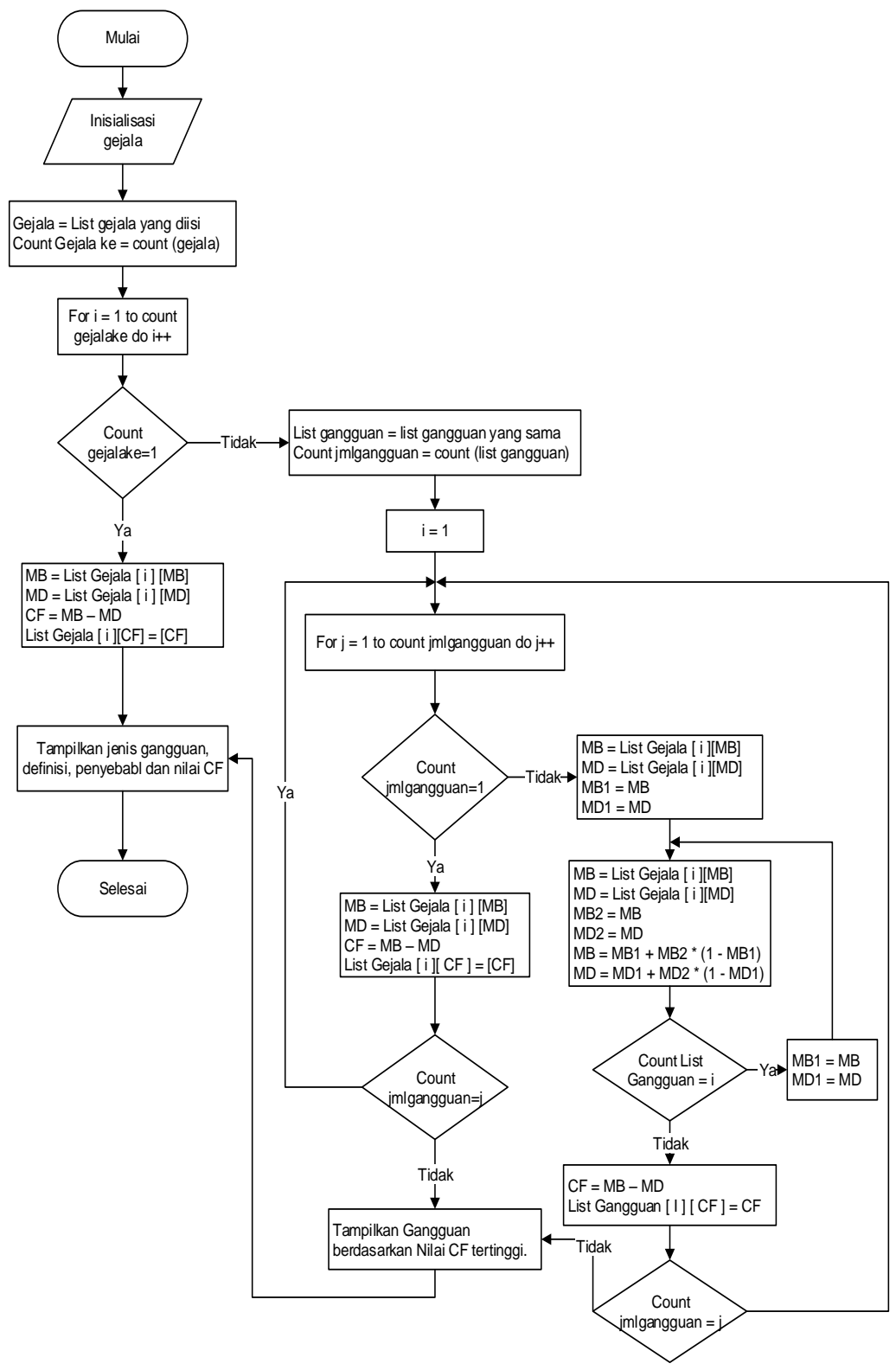

Gambar 1. Flowchart Sistem Pakar Diagnosa Kanker Reproduksi Wanita

Untuk mengetahui hasil diagnosa penyakit kanker reproduksi wanita, maka dilakukan pengujian proses diagnosa. Pada pengujian pertama, diberikan beberapa masukan gejala yang dirasakan antara lain: 1). Haid tidak normal serta dalam jumlah banyak, 2). Sering timbul rasa gatal berlebihan di Vagina, 3). Sering timbul rasa sakit serta berat pada panggul, 4). Sering nyeri saat melakukan hubungan seksual, 5). Siklus menstruasi tidak normal.

Dari gejala tersebut diperoleh bobot kepastian pada setiap gejala yang dipilih, sehingga menghasilkan besarnya MB dan MD berdasarkan gejala yang dipilih. Setelah diperoleh nilai MB dan MD, maka selanjutnya dilakukan proses menghitung besarnya nilai kepastian (certainty factor), yaitu sebagai berikut: 
IF G004, dengan MB[h,e1] $=0.7, \mathrm{MD}[\mathrm{h}, \mathrm{e} 1]=0.3$

AND G016, dengan MB[h,e2] $=0.75$, $M D[h, e 2]=0.25$,

AND G019, dengan $\mathrm{MB}[\mathrm{h}, \mathrm{e} 3]=0.77, \mathrm{MD}[\mathrm{h}, \mathrm{e} 3]=0.23$,

AND G020, dengan MB[h,e4] $=0.75$, MD[h,e4] $=0.25$,

AND G025 MB[h,e5]=0.7, MD[h,e5]=0.3.

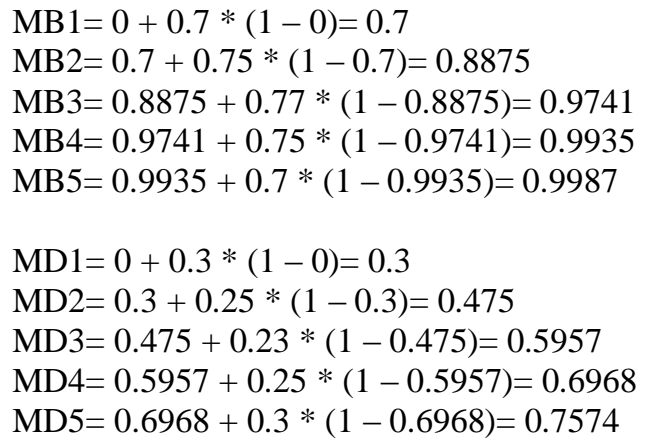

\section{$\mathrm{CF}[\mathrm{MB}, \mathrm{MD}]=0.9987-0.7574=0.2413$}

Setelah proses pengujian tersebut berhasil dilakukan, hasil perhitungan dari sistem kemungkinan penyakit adalah Kista Ovarium dengan nilai certainty factor adalah 0,2413. Maka ditampilkan hasil diagnosa kemungkinan penyakitnya dalah Kista dengan nilai faktor kerpercayaan $24 \%$.

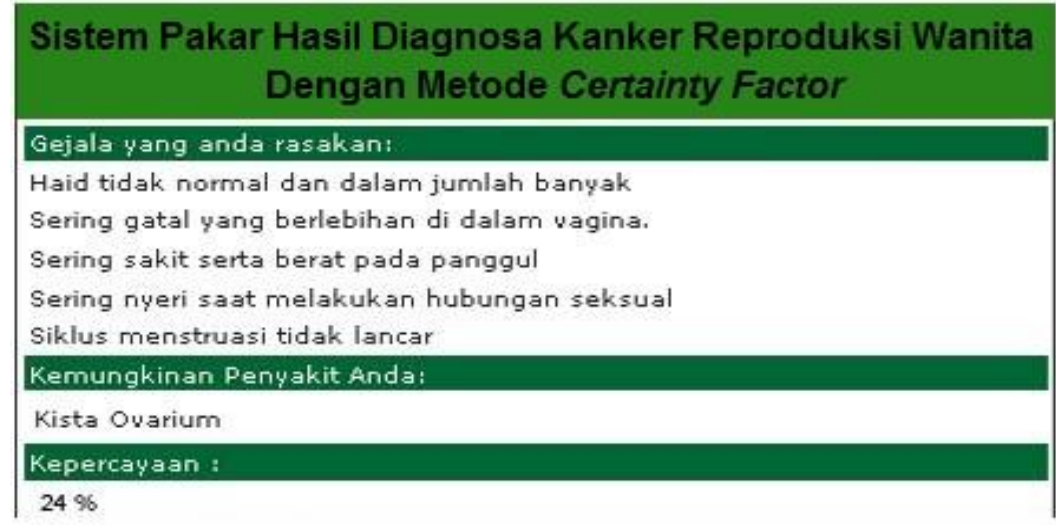

Gambar 2. Tampilan Hasil Diagnosa

\section{KESIMPULAN}

Berdasarkan hasil penelitian dan pembahasan yang telah dilakukan, dapat disimpulkan bahwa:

1. Aplikasi sistem pakar untuk mendiagnosa penyakit kanker reproduksi wanita adalah suatu aplikasi untuk mendiagnosa awal penyakit kanker reproduksi wanita berdasarkan pengetahuan dari para pakar dan studi pustaka.

2. Dengan adanya akses online berbasis web maka masyarakat khususnya untuk para wanita dapat mendiagnosa awal kemungkinan penyakit kanker reproduksi wanita yang dideritanya sebelum mengambil tindakan lebih lanjut seperti konsultasi ke dokter atau tes laboratorium di rumah sakit.

3. Nilai kepercayaan yang dihasilkan dari sistem ini sama dengan hasil perhitungan secara manual dengan menggunakan teori Certainty Factor. Sehingga keakuratan hasilnya sudah sesuai dengan perhitungan yang diharapkan.

4. Aplikasi sistem pakar ini dapat menjadi sarana untuk menyimpan pengetahuan tentang penyakit kanker reproduksi wanita dan pengobatan herbalnya dari pakar atau ahlinya.

\section{REFERENCES}

[1] Kementerian Kesehatan RI, Panduan Penatalaksanaan Kanker Serviks. Jakarta: Komite Penanggulangan Kanker Nasional, 2015. Sukmawati Anggraeni Putri | http://ejurnal.stmik-budidarma.ac.id/index.php/mib | Page | 67 
[2] Y. Faisal, Penyakit Kandungan. Jakarta: Pustaka Populer Obor, 2008

[3] H. Stepahnie and H. Seng, "Penerapan Metode Certainty Factor dalam Sistem Pakar Pendeteksi Resiko Osteoporosis dan Osteoarthritis," Issn 2355-3286, vol. VII, no. 2, pp. 59-69, 2015.

[4] Kusrini, "Penggunaan Certainty Factor dalam Sistem Pakar untuk Melakukan Diagnosis dan Memberikan Terapi Penyakit Epilepsi dan Keluarganya Penggunaan Certainty Factor dalam Sistem Pakar," no. April, 2016.

[5] J. Giarattano and G. Riley, Expert System Principles and Programming. Boston: PWS Publising Company, 1994

[6] Indah Kamaladewi, Mengenal dan Mencegah 7 Kanker Pada Wanita: Cara Alami Deteksi Dini. Komunitas Buku IRT, 2017.

[7] I. Sumatorno, D. Arisandi, A. P. U. Siahaan, and M. Mesran, "Expert System of Catfish Disease Determinants Using Certainty Factor Method," Int. J. Recent Trends Eng. Res., vol. 3, no. 8, pp. 202-209, 2017.

[8] Yeni Lestari Nasution, M. Mesran, S. Suginam, and F. Fadlina, "SISTEM PAKAR UNTUK MENDIAGNOSIS PENYAKIT TUMOR OTAK MENGGUNAKAN METODE CERTAINTY FACTOR (CF),” J. INFOTEK, vol. 2, no. 1, Feb. 2017.

[9] R. P. Tanjung and M. Mesran, "SISTEM PAKAR MENDETEKSI KERUSAKAN MESIN LAS INVERTER DENGAN METODE CERTAINTYFACTOR,” Maj. Ilm. INFOTEK, vol. 2, no. 1, pp. 62-64, 2017.

[10] N. A. Hasibuan, K. Yusmiarti, F. T. Waruwu, and R. Rahim, "Expert systems with genetics probability," Int. J. Res. Sci. Eng., vol. 3 , no. 2, pp. 112-116, 2017.

[11] J. Simarmata, Pengenalan Teknologi Komputer dan Informasi. Yogyakarta: Andi, 2006.

[12] D. P. Utomo and S. D. Nasution, "SISTEM PAKAR MENDETEKSI KERUSAKAN TONER DENGAN MENGGUNAKAN METODE CASE BASED-REASONING," J. Ris. Komput. (JURIKOM, vol. 3, no. 5, pp. 3-6, 2016.

[13] S. W. Nasution, N. A. Hasibuan, and P. Ramadhani, "Sistem Pakar Diagnosa Anoreksia Nervosa Menerapkan Metode Case Based Reasoning," Konf. Nas. Teknol. Inf. dan Komput., vol. I, pp. 52-56, 2017.

[14] M. Mesran et al., "Expert System for Disease Risk Based on Lifestyle with Fuzzy Mamdani," Int. J. Eng. Technol., vol. 7, no. 2.3, pp. $88-91,2018$.

[15] N. A. Hasibuan, H. Sunandar, S. Alas, and Suginam, "Sistem Pakar Mendiagnosa Penyakit Kaki Gajah Mengguanakan Metode Certainty Factor," J. Ris. Sist. Inf. dan Tek. Inform., vol. 2, no. 1, pp. 29-39, 2017.

[16] A. A. H. S. Gulo and M. Syahrizal, "PERANCANGAN APLIKASI SISTEM PAKAR MENDIAGNOSA PENYAKIT HEMOFILIA PADA MANUSIA MENERAPKAN METODE CASE BASED REASONING," J. Pelita Inform., vol. 17, no. 1, pp. 24-29, 2018.

[17] J. Simarmata, Rekayasan Perangkat Lunak. Bandung: Andi Offset, 2015.

[18] M. Syahrizal, "SISTEM PAKAR UNTUK MENGIDENTIFIKASI KERUSAKAN PADA MOBIL TOYOTA DENGAN BEST FIRST SEARCH BERBASIS WAP," Maj. Ilm. INTI, vol. 1, no. 1, pp. 53-57, 2013.

[19] H. Nurdiyanto and P. H. Kuncoro, "Expert System for Measuring the Sugar-Content in Sugarcane Using Forward Chaining Method," in 4th Asian Academic Society International Conference (AASIC), 2016, pp. 527-533.

[20] R. R. Fanny, N. A. Hasibuan, and E. Buulolo, "PERANCANGAN SISTEM PAKAR DIAGNOSA PENYAKIT ASIDOSIS TUBULUS RENALIS MENGGUNAKAN METODE CERTAINTY FACTOR DENGAN PENULUSURAN FORWARD CHAINING," MEDIA Inform. BUDIDARMA, vol. 1, no. 1, Feb. 2017. 